\title{
Moral challenges in handling pregnant school adolescents in Tanga municipality, Tanzania
}

\author{
S S Mkumbugo, ${ }^{B}$ BSc, MBE; J E Shayo, ${ }^{1}$ BSC, MA, MBE; D Mloka, ${ }^{2}$ BSc, MSc, PhD \\ 'Department of Bioethics and Health Professionalism, Muhimbili University of Health and Allied Science, Dar es Salaam, United Republic of Tanzania \\ ${ }^{2}$ Department of Pharmaceutical Microbiology, Muhimbili University of Health and Allied Science, Dar es Salaam, United Republic of Tanzania
}

Corresponding author:S S Mkumbungo (mkumbugo@yahoo.com)

\begin{abstract}
Background. In Tanzania, $~ 8000$ girls drop out of school as a result of pregnancy every year, and it has been reported that this group is faced with discrimination. Mishandling of pregnant adolescents may be one of the factors for this discrimination, and may lead them to opt for risky actions such as unsafe abortions, abandonment of newborns and even suicide.

Objectives. To explore the moral challenges in handling pregnant school adolescents in Tanga municipality, Tanzania.

Methods. This was an exploratory study that used purposive sampling and qualitative methods of data collection. Content analysis methods were used to identify themes from data scripts.

Results. A total of 21 participants were involved, including teachers, parents/guardians, community leaders and religious scholars. Three main themes were identified: parents' decisions on the fate of pregnant school adolescents; education policy and laws with regards to school pregnancy cases; and discrimination in handling pregnant school adolescents.

Conclusion. From the findings of this study, it is concluded that there are moral challenges in handling pregnant school adolescents as a result of implementing education policy, laws and community culture that breach bioethical principles. The study recommends that the government revise the current education regulations to eliminate gender discrimination and promote equality in education.
\end{abstract}

S Afr J Bioethics Law 2020;13(1):68-72. https://doi.org/10.7196/SAJBL.2020.v13i1.684

An adolescent is a person aged between 10 and 19 years. ${ }^{[1]}$ Despite various strategies to fight against school adolescent pregnancy, the problem remains in many countries, including Tanzania. Approximately 15 million adolescents become mothers every year, accounting for more than $10 \%$ of births worldwide. ${ }^{[1]}$ Developing and middle-income countries account for $95 \%$ of world births to adolescents, as over 2 million girls give birth before reaching the age of 15 every year. ${ }^{[2]}$ In Tanzania, pregnancy is the leading cause of school dropout for girls. ${ }^{[3]}$ In 2010, more than 8000 girls dropped out of school owing to pregnancy, including $\sim 160$ girls in primary school and over 6300 in secondary schools. ${ }^{[4]}$ Pregnant school adolescents are vulnerable because they are young, pregnant and under the authority of others. ${ }^{[5]}$ They rely on parents or teachers to decide and defend their interests. Factors such as education policy, laws and community culture may influence parents' and teachers' decisions in handling pregnant school adolescents. In Tanzania, for instance, a girl is expelled from the school as soon as it is proved that she is pregnant. ${ }^{[3]}$ This may influence the decision of handlers of pregnant school adolescents, and may lead to violations of ethical principles. Studies show that pregnant school adolescents are faced with discriminatory acts from other students, neighbours and some members of the family, which may lead them to opt for risky actions such as unsafe abortions, abandonment of newborns and even suicide. ${ }^{[6]}$ In 2003, 14\% of all unsafe abortions in developing countries involved adolescent girls. ${ }^{[7]}$ Handlers of pregnant school adolescents, who may include parents, teachers and community leaders, may be faced with challenges or restrictions that may result in improper handling of pregnant school adolescents. This study will explore the moral challenges involved in handling pregnant school adolescents in Tanga municipality, Tanzania.

\section{Methods}

This was an exploratory study conducted in Tanga municipality, in north-east Tanzania. The study population involved four groups: parents/guardians $(P)$, education policy implementers (teachers $(T)$ and education officers (EO)), community leaders $(\mathrm{CL})$ and religious scholars (RS). Community leaders in this study include ward executive officers, street executive officers and street chairpersons. Criteriontype purposive sampling was used, where experience in dealing with school pregnancy cases was used as the criterion for sample selection. ${ }^{[8]}$ A total of 21 participants was obtained. Focus group discussions and in-depth interviews were used. The in-depth interview method was used to obtain detailed information about a study participant's thoughts and perceptions, in a safe and relaxed environment. This was particularly useful in dealing with sensitive participants such as parents, who usually cannot speak openly in front of other people with regard to matters of school pregnancy, as it is looked upon negatively in Tanzanian society, and it is a criminal offence. Focus group interviews were used to obtain a broader view from participants in terms of beliefs and their experiences with regard to adolescent pregnancy. Central questions were used to initiate both focus group and in-depth interview discussions. Content 
analysis was used to guide the analysis of information in this study. Initial transcription of data was done in Swahili, and later translated to English by the researchers. Both the Swahili and English data transcripts were given to a language expert to ensure accuracy and correct language translation. The emerging themes were checked several times by the three authors to ensure that the reported results are true and accurate. The benefits and risks of participating in this study were explained to all potential participants, and only individuals who gave informed consent were enrolled. Ethical clearance from the Research and Publication Committee of Muhimbili University of Health and Allied Sciences was obtained before conducting this study (ref. no. DA.287/298/01A/2018). Permission to conduct this study in Tanga was given by the director of Tanga city council (ref. no. TCC/E.10/02/C/82).

\section{Results}

A total of 21 participants were involved in interviews. Among them were 4 teachers, 1 education officer, 4 parents, 3 community leaders and 9 religious scholars. The age of participants ranged from 19 to 70 years. The findings of the study are presented based on three main themes and subthemes obtained from data analysis (Table 1).

\section{Theme 1: Parents' decision on fate of pregnant school adolescents}

This theme was divided into two sub-themes: the option of marriage v. legal action against the responsible man; and the influence of the family's income status on the parents' decision.

\section{Sub-theme 1: Option of marriage v. legal action against responsible man}

The study found that parents of pregnant students tend to look for the responsible men, with the primary aim of getting financial support for taking care of the pregnant girl and/or to arrange a wedding with the girl. This may be associated with the loss of opportunity to continue with school, and poor socioeconomic conditions. Legal action is considered necessary if the responsible man does not comply with these demands. One mother said:

'When we got responsible man, he accepted the responsibility, so we agreed on how he will take care of the pregnancy in terms of financial cost. So there were no further criminal procedures for our case, and at the end they got married' (P1, female, age 53 years).

The custom of marrying pregnant adolescents to the responsible men was supported by the grandfather of a pregnant girl, who said that:

'I think that a man who is responsible should be forced to marry a pregnant school daughter; legal actions should be taken against him if he doesn't accept to marry her' (P2, male, aged 60 - 70 years).
In some cases, parents seemed to become very angry when a daughter fell pregnant, but calmed down when the family of the responsible man agreed to accept a marriage with the pregnant daughter. One parent said:

'Because of this co-operation, we did not report the case for legal actions so that the boy continued with education [...] the boy completed his secondary education and they got married' (P4, male, aged 40 - 50 years).

\section{Sub-theme 2: Influence of family income status on parents' decision}

Family economic status was found to influence the decision of parents on the fate of pregnant schoolgoing adolescents. Seemingly well-off families had more options in deciding the fate of a pregnant daughter, including moving her to a private school. An education officer said:

'This girl was expelled from the government school after she got pregnant, but after delivery, her parents were able to pay for private school fees where she started form 1' (EO, male, aged 40 years).

As many families in Tanga are economically poor, the use of little saved money for educational costs was found to influence parents reactions to their pregnant schoolgoing daughter. It has been revealed that parents normally respond with harshness when they think about the money invested in education. A father said:

'I used a lot of money to transfer her to the boarding school expecting that she will do well in the boarding school [...] but they did their stupidity and she got pregnant. I was very angry about that, I did not want to see her' (P4, male, aged 40 - 50 years).

\section{Theme 2: Education policy and laws with regard to school pregnancy cases}

This theme was divided into two sub-themes: proof of adolescent pregnancy at school, and influence of education policy in handling pregnant schoolgoing adolescents.

\section{Sub-theme 1: Proof of adolescent pregnancy at school}

National education policy and school regulations require that a student pregnancy is confirmed by a qualified medical doctor. However, it was found that pregnancy in adolescent school girls is usually proved through routine tests done at schools without the consent of the parents or assent of the students. An education officer said:

'In secondary schools we have pregnant test programmes, especially after opening the school for new term [...] if pregnant test confirms that a certain student is pregnant, we start the

\section{Table 1. Themes and sub-themes identified}

Theme
1 Parents' decision on fate of pregnant schoolgoing adolescent

2 Education policy and laws

3 Discrimination in handling pregnant schoolgoing adolescent
Sub-theme

Option of marriage v. legal action against responsible man Influence of family income status on parents' decision Proof of adolescent pregnancy Influence of education policy Gender discrimination Discrimination based on school adolescent's character 
interrogation with her so that we know the man who is responsible for the pregnan[cy].' (EO, male, aged 40 years).

In some cases, there may be a rumour in the school, or teachers may suspect that a certain student is pregnant. They then take her to a hospital for a pregnancy test. A teacher said:

'When we get information that there is student who is said to be pregnant, we take her to the hospital for pregnan[cy] test in order to get proof of information' (T2, male, aged 40 years).

\section{Sub-theme 2: Influence of education policy in handling pregnant schoolgoing adolescents}

The study revealed variation in levels of strictness in adherence to and implementation of education policy that influenced the judgement of teachers and parents when handling pregnant schoolgoing adolescents. Under past governmental leaderships, teachers had room to override the existing policy by making local arrangements to help pregnant schoolgoing adolescents with good academic records to continue with classes after delivery. A class teacher might list a pregnant student as sick until she was able be return to class. One education officer said that:

'If she get pregnant while in form 1 or form 2, we used to give her a second chance in the class after delivery. But the help was possible before the announcement of our president that pregnant school adolescents should not be allowed to get back into classes' (EO, male, aged 40 years).

Parents also seemed to be aware of changes in policy implementation that have diminished their options in deciding the fate of pregnant schoolgoing adolescents. One parent said:

'School pregnancy is a tough issue in the current leadership; it was better during past leadership where a pregnant student could deliver her child and get back to class' (P1, female, aged 53 years).

Although pregnancy before marriage is not accepted in the major religions in Tanzania, religious scholars who participated in this study were found to disagree with the expulsion of pregnant adolescents from school. One said:

'The government is taking too tight decision against pregnant school adolescents; they should prepare alternative means to make sure that they proceed with education' (RS2, male, aged 46 years).

\section{Theme 3: Discrimination in handling pregnant schoolgoing adolescents}

This theme was divided into two sub-themes: gender discrimination in school pregnancy cases; and discrimination based on school adolescents' character.

\section{Sub-theme 1: Gender discrimination in school pregnancy cases} According to school regulations, fornication and pregnancy are offences against morality that should lead to the expulsion of students. However, the present study revealed that an intensive investigation is normally conducted around a schoolgirl to prove her pregnancy, so that she is expelled from school, but no investigation is done on school boys who engage in fornication and may be responsible for the girl's pregnancy. One teacher said:
'I remember in 2013 there was a male student called Munyambu [pseudonym], [who] impregnated a female student of the same school called Katungwa [pseudonym]. No follow-up was done on Munyambu although every teacher knew about this incident' (T4, female, aged $30-35$ years).

Teachers in this study thought that it was common for girls to be expelled for pregnancy, while a boy/man responsible for a student pregnancy goes free. This is because it is difficult to establish the evidence against the responsible men. A teacher said:

'I think that the most affected person is the pregnant school adolescent herself, because she is going home, while the responsible man proceeds with study if he is a student' $(\mathrm{T} 3$, female, aged 37 years)

\section{Sub-theme 2: Discrimination based on school adolescents' character}

The majority of the study respondents thought that the previous behaviour of a pregnant schoolgoing adolescent, such as academic performance and discipline, might influence the decision about the fate of the respective adolescent. They thought that some pregnant students needed more help than others, owing to differences in their background. One teacher said:

'First we need to know what kind of a girl got pregnant; if we find that the girl is very bright in class, it becomes painful to us, it is very sad. But if we find that a schoolgirl who gets pregnant was not serious in class, we just let her go' (T3, female, aged 37 years).

Most teachers seemed to show support and empathy to students who seemed to be serious about studying and who they labelled as 'good students', while being willing to abandon those who they named as 'bad students'. A teacher said:

'There are some school adolescents who engage in risky behaviours that originated from home; they are not serious in their study. We don't care if they get pregnant' (T1, male, 58 aged years).

\section{Discussion}

The findings of this study suggest that a parent's most common choice on the fate of a pregnant schoolgoing adolescent in Tanga is marriage to the responsible man. Such a marriage may be associated with the loss of opportunity to continue with education, or with poor socioeconomic conditions. A study conducted in Tanga by Nyakubega ${ }^{[9]}$ reported that most school pregnancy cases occurred in families of low socioeconomic status. Similar findings were reported by $\mathrm{Ara}^{[10]}$ in Pakistan, where, for families facing chronic poverty, marriage often seemed to be the best way to safeguard a girl's future and lighten the economic burden. However, there is a moral issue of consent and/or assent with regard to marriage to the man responsible for the pregnancy. The marriage of a pregnant school adolescent to the responsible man seemed to be a forced act. It is ethically unacceptable for the family to force the marriage of a pregnant schoolgoing adolescent to the responsible man, as it violates the principle of autonomy.

The implementation of current national education policy as interpreted by teachers was found to create discrimination, as narrated by teachers who participated in this study. Teachers seemed to give preferential treatment to pregnant students with 
good academic records over those with poor ones. This is ethically questionable, as it may constitute unfair discrimination. It is unjust to class some pregnant schoolgoing adolescents as 'bad students'. Long-term health problems, extreme poverty and orphanage life are among the reasons that may cause a student to seem lazy and to score low marks in exams. ${ }^{[1]]}$ Therefore teachers should aim to help all pregnant school adolescents, regardless of their academic records.

Furthermore, it was found in this study that pregnancy in adolescent schoolgirls is confirmed through routine examinations performed at schools without the consent of the parents or assent of the student. Pregnancy testing procedures are not directly mentioned in the national education policy; however, school regulations require that pregnancy should be confirmed by a qualified medical doctor. The result of the pregnancy test must be presented at a school board meeting, and this is used as evidence for the board to terminate the pregnant student from the school. Teachers may arrange the day and time for conducting pregnancy tests without informing students or parents. This action violates individual autonomy. Parents and students should be informed of the importance of conducting pregnancy tests, to enable them to prepare psychologically if a student is found to be pregnant.

It is practice in Tanzanian schools that investigations are initiated when there is a rumour that a schoolgirl is pregnant. However, no investigations are conducted when there is a rumour that a schoolboy has impregnated a schoolgirl, or any other woman. This is a form of gender discrimination. It is ethically unacceptable, as school regulations list fornication and pregnancy as offences against morality that should lead to expulsion of students of both sexes. In a study conducted by Assey ${ }^{[12]}$ in Temeke, Dar es Salaam, it was found that such discriminatory practice was usually attributed to the lack of available evidence to establish a case against a schoolboy. Expenses associated with conducting DNA tests to identify the male responsible for a pregnancy are a barrier to ensuring justice between girls and boys in such a situation. ${ }^{[12]}$ Unfair treatment of girls v. boys with regard to consequences in cases of school pregnancy have led to disparities in numbers of educated and qualified girls compared with boys. A study conducted in Dar es Salaam by Shadrack ${ }^{[13]}$ revealed that the reasons for low numbers of women in workplaces included low levels of female education. Gender inequality as a result of the expulsion of schoolgirls due to pregnancy may directly affect Tanzania's vision to attain the United Nations Sustainable Development Goals (SDGs) agenda by 2030, and in particular SDGs $1-5,8$ and 10. It has been documented that adolescent mothers often remain in poverty, with low employment skills, and their children are at increased risk for early pregnancy, poverty and poorer academic outcomes. ${ }^{[14]}$ Measures should therefore be undertaken to empower pregnant adolescents.

Actually there is no explicit statement in the Tanzanian Education Act of 1978 that pregnancy should lead to expulsion from school, but the same act empowers the minister of education to formulate the education policy in which an offence against morality is listed as expellable offence for students. The Act also empowers the minister of education to delegate the interpretation of the education policy and formulation of school regulations to respective school boards where pregnancy, fornication and abortion are normally interpreted as offences against morality. Expelling pregnant schoolgoing adolescents from government schools has also been insisted upon by the current President. The implementation of the presidential decree has led to many pregnant schoolgoing adolescents being expelled from schools on the Tanzanian mainland. This is contrary to Zanzibar, which is a semi-autonomous part of the United Republic of Tanzania. In Zanzibar, the Spinster and Single Parent Child Protection Act No. 4 of 2005 allows pregnant students to return to and continue with school after delivery. ${ }^{[15]}$

\section{Conclusion}

The exclusion of pregnant students from government schools is a central cause of challenges that may lead to forced marriages, the privileging of pregnant students with good academic records over those with poor ones and/or schools carrying out pregnancy tests without consent. Handlers of pregnant schoolgoing adolescents in Tanga are faced with moral challenges when trying to make decisions that they think are beneficial in dealing with school pregnancy cases, and none of the approaches provide solutions that adhere to all four universal ethical principles of autonomy, non-maleficence, beneficence and justice, and thus may cause either psychological, socioeconomic or physical harm to the vulnerable schoolgoing adolescent who is pregnant.

Based on the results of this study, it is recommended that education policy and law should be revised to allow pregnant schoolgoing adolescents to continue with their education. In addition, the office of social welfare should be used to give psychological advice to pregnant schoolgoing adolescents and parents for better decision-making on school pregnancy cases. Further studies should be conducted on the moral issues of handling pregnant school adolescents during and after legal procedures in Tanzania.

Acknowledgements. The research reported in this publication was supported by Dartmouth-MUHAS Research Ethics Training Project (DMRET) under the grant number 5R25TW007693-08.

Author contributions. SSM is the corresponding author; all authors made equal contributions to the article.

Funding. The research reported in this publication was funded by DMRET. Conflicts of interest. None

1. World Health Organization. Adolescent Pregnancy: Issues in Adolescent Health and Development. Geneva: WHO, 2004. https://apps.who.int/iris/bitstream/ handle/10665/42903/9241591455_eng.pdf;jsessionid=77CDA108F572CB8564B D56B2356E7B87? sequence=1 (accessed 10 January 2020 ).

2. United Nations Educational, Scientific and Cultural Organization. Developing an Education Sector Response to Early and Unintended Pregnancy. Paris: UNESCO, 2014 (conference version).

3. Kiluvia F. Gender and Sexuality Notions as Determinants of School Pregnancies In Tanzania: A Case Of Iringa Rural District. Master's thesis. Rotterdam: Erasmus University, 2001.

4. Mbelwa I. Teen pregnancy: Children having children in Tanzania. SSRN Electron J 2012:2028369. https://doi.org/10.2139/ssrn.2028369

5. Beauchamp TL, Childress JF. Principles of Biomedical Ethics. 7th ed. New York: Oxford University Press, 2013. https://doi.org//10.1093/occmed/kqu158

6. Meneses JD, Saratan CT. Antecedents and consequences of teenage pregnancy: A phenomenological study. Int J Med Health Res 2015;1(2):1-5.

7. United Nations Children's Fund. Children and Women in Tanzania Volume Mainland. 2011. https://www.unicef.org/about/annualreport/files/Tanzania COAR_2012.pdf (accessed 15 March 2020).

8. Suri $H$. Purposeful sampling in qualitative research synthesis. Qual Res J 2011:11:63-75. https://doi.org//10. 3316/QRJ1102063 
9. Nyakubega P. Factors associated with adolescent pregnancies among secondary school students. A study from Tanga Tanzania. Afr J Online 2010;16(1). https://doi. org/10.4314/dmsj.v16i1.53350

10. Ara N. Gender discrimination in education - a barrier in development of female education at higher secondary level. Interdisciplin J Contemporary Res Bus 2012;4(5):330-339.

11. Brighton L. Factors affecting student performance in certificate of secondary education examination in Newala District, Mtwara Region. Master's thesis. Dar es Salaam: Open University of Tanzania, 2017. http://repository.out.ac.tz/1748 (accessed 7 April 2020)

12. Assey S. A critical analysis of the expulsion of pregnant girls from school: A case study of Temeke District, Dar es Salaam, Tanzania. Master's dissertation. Harare: University of Zimbabwe, 2012.
13. Shadrack B. Assessment of affirmative action practices at workplace: A Case of Ministry of Community Development Gender and Children (MCDGC). Master's dissertation. Morogoro: Mzumbe University, 2015.

14. Furstenberg F. Teen pregnancy and poverty: 30 -year-study confirms that living in neighbourhoods, not teen motherhood, perpetuates poverty. Council on Contemporary Family 2008. https://contemporaryfamilies.org/teen-pregnancyand-poverty/ (accessed 10 January 2020).

15. Spinsters and Single Parent Child Protection Act, 2005. Zanzibar. http://www. zanzibarassembly.go.tz/act_2005/act_4.pdf (accessed 10 May 2020).

Accepted 15 January 2020. 